\title{
IS Skills of Business Students in Transition from Secondary to Tertiary Studies
}

\author{
Rodney Turner \\ Victoria University of Technology, Melbourne, 8001
}

rod.turner@vu.edu.au

\begin{abstract}
This paper reports an analysis of IT software skills of some Victorian students on entry to first year tertiary studies in Business along with an analysis of their performance in "Office" type application assignments. The assumption that youth of today are IT literate on exit from school is questioned. Despite survey results suggesting a high level of skill in word processing and, to a lesser extent in spreadsheets, results on assignments in these areas may suggest students perceive their skills as being better than their actual performance. In crowded curricula, where there is pressure to include ever more material at the expense of more traditional topics, word processing and spreadsheet applications are sometimes suggested for removal. The study reported here finds little evidence that these topics should be removed from the curriculum at this stage.
\end{abstract}

Keywords: IT skills, software skills, software knowledge, secondary students, tertiary students

\section{Introduction}

In the last six years or so there has been a great emphasis placed on IT in the secondary curriculum in Victoria. As more students have existing skills from exposure to a range of software applications in secondary schools, is the time near when some of these skills can be assumed? Some would argue that this is the case and that some applications such as word processing should be moved out of the tertiary curriculum. Yet as has been observed by Stoner (1999), some students entering tertiary studies lack even a basic IT skills manifesting in a fear of the technology. He refers to a 'tension' between the common belief that youth of today are IT literate and academic staff views querying this assumption. In a crowded curriculum there is a certain attractiveness in assuming a certain level of IT literacy as there is seldom sufficient time to cover all topics and applications adequately.

\section{Other studies}

As reported by Stoner (1999), the IT skills students bring to from secondary education have important implications for what IT skills are taught in the higher education. There is little doubt that employers in particular are seeking graduates with ever increasing skills in IT and revising curricula to take into account the demands of business is a continuing process (Heiat et. al.). Gazely \& Pybus (1997) suggest

Material published as part of these proceedings, either on-line or in print, is copyrighted by Informing Science. Permission to make digital or paper copy of part or all of these works for personal or classroom use is granted without fee provided that the copies are not made or distributed for profit or commercial advantage AND that copies 1) bear this notice in full and 2) give the full citation on the first page. It is permissible to abstract these works so long as credit is given. To copy in all other cases or to republish or to post on a server or to redistribute to lists requires specific permission from the publisher at Publisher@InformingScience.org that some students are entering tertiary studies still lacking basic IT skills and displaying computer phobias to varying degrees.

Young (1999), reporting the results of a survey of IT faculty covering what IT skills were expected of students, showed that low end skills such as email, word processing and web searching were expected. Students were not expected to use high- 
end skills such as database or creating macros. Further, he reported that faculty were largely unfamiliar with higher end applications themselves.

Few studies have explicitly investigated the IT skills of commencing tertiary students. Gazely \& Pybus (1997) and Marriott (1997) have looked at the integration of IT skills into accounting courses and Stoner (1999) has investigated the IT skills of commencing accounting students in a Scottish university. Of these, only Marriott (1997) has carried out quantitative assessment of IT skills via short tests. In Australia, Oliver (1993) found that there was a wide diversity of IT skills among school pupils including those who lacked even the basic IT skills. Lim \& Kendle (2001) in a study involving first year science students, noted that "Government policy is being formulated on the assumption that (high-) school leavers and university graduates are computer literate" and that "universities are also developing and implementing policy based on the assumption that students are computer literate". They observed a general increase in general IT skills over the last few years to 2001, but these skills were not uniformly high even with word processing. Stein (2002) reported first year university student self-perception of computer knowledge and confidence, and previous experience in the use of computers and ICT packages. He found these self-assessed parameters had changed little over a four year period from 1998. He also noted that access to the internet from home had jumped dramatically in that period, whereas use in applications such as spreadsheets and database had actually dropped. In a cautionary note however Karsten \& Roth (1998) suggest that course grades do not in themselves contribute much about student confidence or motivation towards IT. This is an important consideration in the outcomes of the study reported in this paper.

\section{Background}

Students enrolled in the Bachelor of Business are required to complete eight core subjects and 16 specialization and elective subjects for their degree. The core computing subject "Computer Applications" is an introductory subject with a workshop component that includes word processing, spreadsheet and database assignments.

\section{Data Collection}

A questionnaire was administered to 260 first year students across three campuses in the Business and Law faculty during the first two weeks of semester one of the 2000 academic year in Victoria. This represents approximately 20 percent of the entire student enrolment in the subject. Students in the faculty enrol at the commencement of their degree in one of several specialization areas including accounting, hospitality, economics, management, law and information systems, thus giving a broad range of career options that may in turn influence attitudes towards and experience in information technology.

All students in the faculty of Business and Law are required to study the subject "Computer Applications" as one of the core subjects prior to studying their specialization areas. Students are not streamed within campus but different campuses have different specializations and so some streaming by interest is in place. However as students were surveyed during the first two weeks of the academic year and most were first year students (a small number of repeat students are included), it is likely that the results reflect the situation in students exiting schools in the capture area of the university.

A total of 243 usable responses were available for analysis for the initial analyses. A sample of 93 results was used to compare the responses to the initial questionnaire with actual performance in assignments in word processing, spreadsheet and database. 


\begin{tabular}{|c|l|}
\hline Skill area & Explanation \\
\hline 1. Use of Windows & $\begin{array}{l}\text { Access applications, store/retrieve/print } \\
\text { files/cut \& paste between applications }\end{array}$ \\
\hline 2. $\begin{array}{l}\text { Building \& using } \\
\text { spreadsheet models } \\
\text { (Excel) }\end{array}$ & Analyse problems and create reports \\
\hline 3. $\begin{array}{l}\text { Use word processing } \\
\text { (Word) }\end{array}$ & Create and edit essays/reports/letters \\
\hline 4. $\begin{array}{l}\text { Use email (Netscape } \\
\text { mail) }\end{array}$ & Send and receive messages \\
\hline 5. $\begin{array}{l}\text { Using the World Wide } \\
\text { Web (Netscape) }\end{array}$ & Accessing \& searching for information \\
\hline 6. $\begin{array}{l}\text { Use s tatistical package } \\
\text { (SPSS) }\end{array}$ & Prepare and analyse statistical data \\
\hline 7. $\begin{array}{l}\text { Use a database appli- } \\
\text { cation (Access) }\end{array}$ & $\begin{array}{l}\text { Create tables, retrieve \& relate data, pre- } \\
\text { pare reports }\end{array}$ \\
\hline
\end{tabular}

Table 1: IS skills areas in the survey. (after Stoner, 199)

\section{Questionnaire Details}

A single page questionnaire was used adapted from Stoner (1999 with permission. The original questionnaire asked for students to self-score on a five point Likert scale three questions on how they rated their skill, how much they used their skill and how confident they were in that skill use. This was applied to seven different software areas covering use of Windows, spreadsheets, word processing, e-mail, the World Wide Web, statistical software (SPSS) and database software. The skill areas covered by the questionnaire are those of Stoner (1999) and are summarized in Table 1. An additional assessment was

\begin{tabular}{|c|c|c|c|}
\hline $\begin{array}{l}\text { How do you rate } \\
\text { your skill? }\end{array}$ & $\begin{array}{l}\text { How much do you } \\
\text { use the software? }\end{array}$ & $\begin{array}{l}\text { How confident are } \\
\text { you in using it? }\end{array}$ & $\begin{array}{l}\text { How important do } \\
\text { you believe it is? }\end{array}$ \\
\hline $\begin{array}{l}\text { 1. Non existent } \\
\text { 2. Some but not } \\
\text { adequate } \\
\text { 3. Adequate, } \\
\text { can get by } \\
\text { 4. Good, can do } \\
\text { most of what } \\
\text { I want to do. } \\
\text { 5. Excellent, } \\
\text { there are no } \\
\text { problems I } \\
\text { cannot solve }\end{array}$ & $\begin{array}{c}\text { 1. Never } \\
\text { 2.Sometimes, not } \\
\text { regularly } \\
\text { 3. Regularly, at } \\
\text { least once a } \\
\text { week } \\
\text { 4. Quite often, } \\
\text { several times } \\
\text { per week } \\
\text { 5.A lot }\end{array}$ & $\begin{array}{c}\text { 1. No confidence } \\
\text { 2. Little confidence } \\
\text { 3. Some confidence } \\
\text { 4. Confident } \\
\text { 5. Very confident }\end{array}$ & $\begin{array}{l}\text { 1. Not at all im- } \\
\text { portant } \\
\text { 2. Not very im- } \\
\text { portant } \\
\text { 3. Reasonably } \\
\text { important } \\
\text { 4. Very impor- } \\
\text { tant } \\
\text { 5. Mandatory or } \\
\text { essential }\end{array}$ \\
\hline
\end{tabular}

Table 2: Meanings attached to the scale responses (Stoner, 1999) 
included that covered how important they felt knowledge of the application was. Details concerning access to a PC at home and the respondent's gender were also sought. A summary of the questionnaire is presented in Table 2.

\section{Analysis of Results}

\section{Item reliability}

Reliability estimates via Cronbach's $\alpha$ were determined for each of the options and is summarised in Table 3. A Cronbach score of 0.7 is considered the minimum value for item reliability.

\begin{tabular}{|l|l|}
\hline Rate skill & 0.80 \\
\hline Usage level & 0.79 \\
\hline Confidence in using & 0.81 \\
\hline Importance & 0.83 \\
\hline
\end{tabular}

Table 3: Cronbach $\alpha$ scores

\section{Gender}

As can be seen in Table 4 below, distribution between genders was fairly even with 46 per cent female and 53 per cent males. One per cent did not identify their gender.

\section{Access to a PC at home}

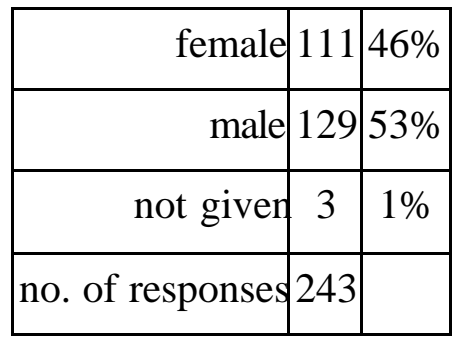

Table 4: Gender breakdown

A high level of access to a PC at home was reported with 201 out of 243 , or 83 per cent claiming access. The level of access within the home however was not determined - no differentiation was made between those who had unlimited access and those who may have to share with family me mbers.

As can be seen in Table 5, access to PCs at home is slightly higher for males than for females with 90 per cent of male students and 82 per cent of females having access.

Table 6 shows the mean scores and standard deviations for self rated skills, use, and confidence in the use of the

\begin{tabular}{|l|l|c|c|}
\hline Gender & & Frequency & Percent \\
\hline Female & No PC & 20 & 18 \\
\hline & Home PC & 90 & 82 \\
\hline Male & No PC & 13 & 10 \\
\hline & Home PC & 114 & 90 \\
\hline
\end{tabular}

Table 5: Access to PC at home (gender breakdown) appipdinatimohthaptmeepeecleimrebitapoetance.

The figures show that students rated their skills lowest in statistics and database software. Interpretation of these figures suggests that for SPSS skills were almost non-existent and is probably not used by many students. It is hardly surprising that there is little or no confidence expressed in using this software yet they felt it was very important as an application. With Access the skill rating was higher possibly reflecting some use in high school assignments by some students although usage varies around the 'sometimes but not regular' level. Again it is not surprising that they express little confidence in using the application.

Rating in the use of spreadsheets, email and the web were similar and centred around the 'adequate, can get by' level. Levels of usage for these applications varied from not regularly to at least once a week and some confidence in the use. Importance of the applications is clearly in the "very important" range.

Windows and word processing applications were the two highest rating applications. The skill level rated as able to perform most of what is needed. Regular usage, at least weekly to several times a week 


\begin{tabular}{|c|c|c|c|c|c|}
\hline \multicolumn{2}{|c|}{ application } & \multirow{2}{*}{$\frac{\text { rate skill }}{3.8}$} & \multirow{2}{*}{$\frac{\text { use }}{3.2}$} & \multirow{2}{*}{$\begin{array}{c}\text { confidence } \\
3.5\end{array}$} & \multirow{2}{*}{$\frac{\text { importance }}{4.3}$} \\
\hline win & mean & & & & \\
\hline & sd & 0.8 & 1.0 & 0.9 & 0.8 \\
\hline \multirow{2}{*}{ SS } & mean & 3.1 & 2.3 & 2.9 & 4.0 \\
\hline & $\mathrm{sd}$ & 0.9 & 1.0 & 1.0 & 0.9 \\
\hline \multirow{2}{*}{ wp } & mean & 4.1 & 3.5 & 3.8 & 4.3 \\
\hline & $\mathrm{sd}$ & 0.9 & 1.1 & 0.9 & 0.8 \\
\hline \multirow{2}{*}{ email } & mean & 3.2 & 2.8 & 3.1 & 4.0 \\
\hline & $\mathrm{sd}$ & 1.3 & 1.5 & 1.3 & 1.0 \\
\hline \multirow{2}{*}{ WWW } & mean & 3.4 & 3.0 & 3.3 & 4.2 \\
\hline & $\mathrm{sd}$ & 1.1 & 1.3 & 1.2 & 0.8 \\
\hline \multirow{2}{*}{ spss } & mean & 1.7 & 1.4 & 1.7 & 3.4 \\
\hline & sd & 0.9 & 0.7 & 0.8 & 1.3 \\
\hline \multirow{2}{*}{ access } & mean & 2.5 & 1.9 & 2.3 & 3.7 \\
\hline & sd & 1.0 & 1.0 & 1.0 & 1.1 \\
\hline
\end{tabular}

Table 6: Statistical analysis of responses

may account for the higher level of confidence. These two applications were seen as important to mandatory applications but most of the selected applications were seen as important.

\section{Performance Comparisons}

Students enrolled in Computer Applications are required to submit assignments for word processing, spreadsheets and database basics as part of the assessment, thus providing an opportunity to compare their performance against their responses to the questionnaire. A convenience sample of 93 was taken to correlate performance aga inst questionnaire ratings.

In Table 7 the correlation coefficients are presented for performance in the appropriate assignment against the skill rating (xxRATE), use (xxUSE), confidence (xxCONF) and importance (xxIMP) - $x x$ representing the actual application (word processing - WP, spreadsheet - SS or database - DB).

Consistently high (a value greater than 0.6) and similar levels of significance for the correlations are present between the skill rating (rate) and use, between skill rating and confidence and between confidence (conf) and use. For each of the three applications the correlations are significant at the .01 levels.

A small correlation was established between word processing performance and rating $(\rho=0.23, p<0.05)$ and between word processing use and rating $(\rho=0.27, p<0.01)$. For performance in spreadsheets and database correlations were small and not significant. 
There was no consistent pattern involving perceived importance of having skills in application. Only word processing gave a small but significant correlation $(\rho=0.23$, $\mathrm{p}<0.05)$ between confidence in using the application and the perceived importance of having the skill.

\section{Discussion}

One of the original unwritten aims of this research was to seek evidence that the time was approaching where it could be assumed that students starting tertiary studies had certain IS skills and that these skills no longer needed to be formally taught at tertiary level. In particular it was felt that the time was close where word processing and perhaps even spreadsheet applications were adequately covered in secondary school thus allowing other applied IS topics to be covered. This indeed is a case put forward by Stoner (1999). Evidence gathered in the present study superficially suggests that Victorian students are even stronger in word processing and other applications that their Scottish counterparts even taking into account the present study took place nearly 18 months

\begin{tabular}{|c|c|c|c|c|c|}
\hline & WP & WPRATE & WPUSE & WPCONF & WPIMP \\
\hline $\begin{array}{l}\text { WP Per- } \\
\text { formance }\end{array}$ & 1.00 & $0.23^{1}$ & $0.27^{2}$ & 0.18 & 0.05 \\
\hline WPRATE & & 1.00 & $0.63^{2}$ & $0.74^{2}$ & 0.14 \\
\hline WPUSE & & & 1.00 & $0.62^{2}$ & 0.20 \\
\hline WPCONF & & & & 1.00 & $0.23^{1}$ \\
\hline \multirow[t]{2}{*}{ WPIMP } & & & & & 1.00 \\
\hline & SS & SSRATE & SSUSE & SSCONF & SSIMP \\
\hline \begin{tabular}{|l|} 
SS Perform- \\
ance
\end{tabular} & 1.00 & 0.06 & -0.03 & 0.11 & -0.11 \\
\hline SSRATE & & 1.00 & $0.65^{2}$ & $0.77^{2}$ & -0.09 \\
\hline SSUSE & & & 1.00 & $0.65^{2}$ & 0.18 \\
\hline SSCONF & & & & 1.00 & 0.00 \\
\hline \multirow[t]{2}{*}{ SSIMP } & & & & & 1.00 \\
\hline & DB & DBRATE & DBUSE & DBCONF & DBIMP \\
\hline $\begin{array}{l}\text { DB Per- } \\
\text { formance }\end{array}$ & 1.00 & 0.14 & 0.16 & 0.11 & 0.15 \\
\hline DBRATE & & 1.00 & $0.65^{2}$ & $0.84^{2}$ & -0.10 \\
\hline DBUSE & & & 1.00 & $0.71^{2}$ & 0.10 \\
\hline DBCONF & & & & 1.00 & 0.05 \\
\hline DBIMP & & & & & 1.00 \\
\hline
\end{tabular}

Table 7: Ratings vs performance later than the Scottish study. However when the results of the survey are compared with the actual performance on assignments in the three specific areas of word processing, spreadsheets and database a less clear picture emerges. Although significant positive correlations exist between the student rating, use and performance in the case of word processing, they are only small. For spreadsheets and database the corresponding correlations are even smaller and are not significant. These results are also consistent with those reported by Lim \& Kendle (2001)

What does this suggest?

1. It may indicate that the performance on the assignments does not measure the actual skills and capabilities in the particular application and that an alternative means of assessing these skills needs to be used.

2. It may also suggest that the skills possessed by students exiting from schools are not as well developed as they are claimed to be. Students may for example, use word processing at a relatively low level, sufficient though to prepare school assignments but deficient in some of the more advanced skills such as styles, table of contents and page numbering. This is a possible scenario given the early administration of the survey in semester one where their skills are more likely to have been influenced by school based activities than by tertiary studies.

3. Students may be overconfident in their ability in the use of the software and in their understanding of the capabilities of the software. Here a situation may be envisaged where they are confident in using 
a small set of features, possibly unaware of the fuller range of capabilities of the software. It may be too, that the high level of access to PCs in the home reported in this study unreasonably influences those students to believe their skills are better developed than they are. This could not be accurately determined using the current data although a slight increase in the correlation (rate vs use) to $\rho=0.26$ $(\mathrm{p}=0.02)$ when comparing PC access. When comparing gender a stronger correlation appears for females $(\rho=0.46, p=0.003)$ than for males $(\rho=0.04, p=0.76)$.

4. The low correlation between rating and performance on tasks may simply be a manifestation of the time difference between administering the survey and the completion of the assignment.

There is some evidence supporting the view that students rating their skills in word processing and their actual performance on assignments in this application are significantly correlated. However the strength of the correlation is weak and the evidence is not strong enough to support the removal or downgrading the importance of word processing. As far as other common office applications such as spreadsheets and database are concerned there is no evidence at all in support of a downgrading in importance. As Lim \& Kendle (2001) suggest, university teaching departments should recognise that incoming undergraduate students are not fully prepared to use IT facilities in their courses. One suggestion by Lim \& Kendle (2001) is for universities to implement compulsory IT training with hurdles that must be crossed before students can proceed further with that subject. The problem with this of course is in the availability of resources to implement such a programme.

The initial aim of this research in seeking evidence supporting the possible reduction in emphasis placed on teaching common Office applications such as word processing at tertiary level is not strongly supported. Although students rate their skills quite highly in word processing and in spreadsheets to a lesser extent, this does not appear to translate into performance on tasks in these applications. More research in this area seems warranted before word processing skills can be accepted in a similar light to writing skills and downgraded in the tertiary business curriculum.

\section{References}

Gazely, A. and L. Pybus (1997). Beyond basic IT skills . Proceedings of the 8th annual CTI-AFM conference, Newport, Gwent. 52-58

Heiat, A., N. Heiat, et al. Future Software Training Needs: Contrast in Needs as Perceived by Business and Academia. Available on-line at: 〈www.gise.org/future software training needs.htm>, [Accessed 11/07/2000]

Karsten, R. \& Roth, R.M. (1998). Computer Self-Efficacy: A Practical Indicator of Student Computer Competency in Introductory IS Courses. Informing Science 1(3): 61-68.

Lim, K. F. \& A. Kendle (2001). Computer and IT skills of Australian first-year university undergraduate students. Chemical Education Journal (CEJ) 5(2): 23 pages.

Marriott, N. (1997). A longitudinal study of student attitudes towards, and ability to use, computers in higher education. Proceedings of the 8th annual CTI-AFM conference, Newport, Gwent.

Oliver, R. (1993). A comparison of students' information technology skills in 1985 and 1991. British Journal of Educational Technology 24((1)): 52-62.

Stein, A. (2002). Preparation for "e-learning": ICT literacy and usage of Australian university students (2001). IRMA2002, Seattle,WA.

Stoner, G. I. (1999). IT is part of youth culture, but are accounting undergraduates confident in IT? Accounting Education(8): 217-237.

Young, J. (1999) Information Technology Skills and the Undergraduate Curriculum. Available on-line at: <www.doit.gmu.edu/survey/itskills.htm>, [Accessed 28/11/2002] 


\section{Biography}

Rodney Turner is a lecturer in the School of Information Systems at Victoria University, Melbourne, Australia since 1989. Prior to this he has worked in industry and was a teacher for 12 years. He is a graduate from Monash University, RMIT and Melbourne CAE with qualifications in science, mathematics education, computer education and information technology. He is currently engaged in research leading towards a $\mathrm{PhD}$. His main research interests are in IS education and the skills required in a changing IS environment.

\section{Acknowledgment}

The author wishes to acknowledge G Stoner's permission to adapt the questionnaire used in this study 